\title{
Correction to: Investigation of Electromagnetic Field Coupling with Twisted Conducting Line by Expanded Chain Matrix
}

\author{
Hyun-Kyo Jung ${ }^{1} \cdot$ Yong-Sun Cho ${ }^{1} \cdot J^{\prime}$ Jong-Suk Ro ${ }^{1} \cdot$ Yong-Seek Chung ${ }^{2} \cdot$ Changyul Cheon $^{3}$
}

Published online: 28 January 2021

(c) The Korean Institute of Electrical Engineers 2021

After publication of this article [1], it was brought to our attention that we had neglected to acknowledge the similarities between this current article and the work of Cho et al. [2]. Specifically, there are similarities in how to use the Chain Matrix between the articles [1,2] although the objective and case studies are different from each other. As such, we are publishing this correction in order to properly reference the authors of the previous work on which parts of this article are based.

Hyun-Kyo Jung

hkjung@snu.ac.kr

Yong-Sun Cho

raphaelz@snu.ac.kr

Jong-Suk Ro

jongsukro@naver.com

Yong-Seek Chung

yschung@kw.ac.kr

Changyul Cheon

changyul@uos.ac.kr

1 Department of Electrical and Computer Engineering, Seoul National University, Seoul, Korea

2 Department of Electronics Convergence Engineering, Kwangwoon University, Seoul, Korea

3 Department of Electrical and Computer Engineering, University of Seoul, Seoul, Korea

\section{References}

1. Cho YS, Ro JS, Chung YS, Cheon C, Jung HK (2013) Investigation of electromagnetic field coupling with twisted conducting line by expanded chain matrix. J Electr Eng Technol 8(2):364-370. https://doi.org/10.5370/JEET.2013.8.2.364

2. Cho JH, Lee JH, Kim HD (2010) Analysis of electromagnetic pulse coupling to twisted cable using chain matrix. J Korean Inst Electromagn Eng Sci 21(7):734-743

Publisher's Note Springer Nature remains neutral with regard to jurisdictional claims in published maps and institutional affiliations. 